\title{
Numerical simulation of mitigation for liquefaction-induced soil deformations in a sandy ground improved by cement grouting
}

Yu Huang · Feng Zhang · Atsushi Yashima •

Weimin Ye

Published online: 21 November 2007

(C) Springer-Verlag 2007

Erratum to: Environ Geol

\section{DOI 10.1007/s00254-007-1069-z}

Unfortunately, this article contains a printing error on the label of the vertical axis in Fig. 7. The correct figure is given below:

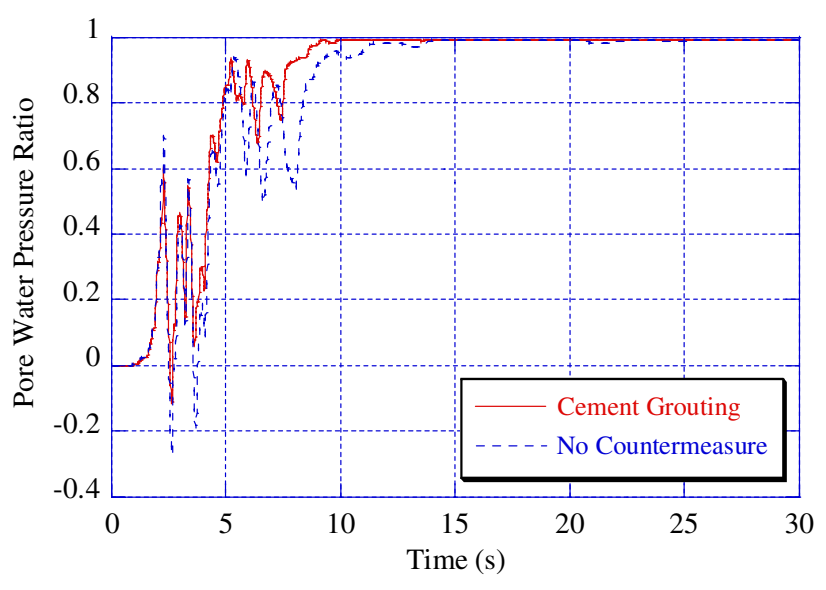

Fig. 7 Time histories of excess pore-water pressure ratios

The online version of the original article can be found under doi:10.1007/s00254-007-1069-z.

Y. Huang $(\varangle) \cdot$ W. Ye

Department of Geotechnical Engineering,

Tongji University,

Shanghai 200092, China

e-mail: yhuang@mail.tongji.edu.cn

F. Zhang

Department of Civil Engineering,

Nagoya Institute of Technology,

Nagoya 466-8555, Japan

A. Yashima

Department of Civil Engineering,

Gifu University, Gifu 501-1193, Japan 